Association for Information Systems

AIS Electronic Library (AISeL)

Wirtschaftsinformatik 2021 Proceedings

Track 7: Digital Services and Smart Product-

Service Systems

\title{
Combining Methods for the Design of Digital Services in Practice: Experiences from a Predictive Costing Service
}

\author{
Fabian Richter \\ Hochschule für Technik und Wirtschaft Dresden \\ Jürgen Anke \\ Hochschule für Technik und Wirtschaft Dresden
}

Follow this and additional works at: https://aisel.aisnet.org/wi2021

Richter, Fabian and Anke, Jürgen, "Combining Methods for the Design of Digital Services in Practice: Experiences from a Predictive Costing Service" (2021). Wirtschaftsinformatik 2021 Proceedings. 1. https://aisel.aisnet.org/wi2021/TDigitalServices/Track07/1

This material is brought to you by the Wirtschaftsinformatik at AIS Electronic Library (AISeL). It has been accepted for inclusion in Wirtschaftsinformatik 2021 Proceedings by an authorized administrator of AIS Electronic Library (AISeL). For more information, please contact elibrary@aisnet.org. 


\title{
Combining Methods for the Design of Digital Services in Practice: Experiences from a Predictive Costing Service
}

\author{
Fabian Richter ${ }^{1}$, and Jürgen Anke ${ }^{1}$ \\ ${ }^{1}$ HTW Dresden, Germany \\ \{fabian.richter, juergen.anke\}@htw-dresden.de
}

\begin{abstract}
Exploiting digital technologies for innovative service offerings as part of the digital transformation has been under discussion for several years. As recent research has shown, practitioners struggle with the systematic design of digital services. Along with the progress in the understanding of digital service systems, academia has proposed various processes and methods which are contributing to a methodology for Service Systems Engineering. However, such methods are rarely applied in practice. In our study, we utilize Action Design Research to evaluate how existing methods can be applied in a project that aims to design a service for predictive costing. Our findings are formalized as a combination of methods and their links. It shows how these methods can be employed to guide the innovation process. Although the generalizability of the results is limited through the single case study approach, the proposed combination of methods provides evidence-based knowledge on Service Systems Engineering, which is relevant for practitioners and researchers alike.
\end{abstract}

Keywords: Digital Services, Service Systems Engineering, Action Design Research, Methodology, Service Innovation

\section{Introduction}

Applying digital technologies for services enable new value propositions and innovative business models. Such digital or smart services thus represent an interesting source of competitive advantage for many companies. However, companies struggle to design economically sustainable digital service offers [1]. Due to the complexity of such systems and the uncertainty in the innovation process, experts from various disciplines have to be involved [2]. Systematic design and development of digital services are addressed by Service Systems Engineering (SSE). Agile engineering processes for such services have been proposed, e.g. the DIN SPEC 33453 [3] or Recombinant Service Systems Engineering [4]. These process models organize the dynamic aspects, e.g. project phases. Concrete methods can be applied to guide the steps required to create intermediate work products, such as business models, service concepts, or system architectures. A variety of methods that address the specifics of digital service systems has become available as a result of recent research.

While the body of knowledge on SSE for digital services is growing, there is little empirical evidence on their suitability and practical application. To inform future 
research on this topic, we concur with Böhmann et al., who call for evidence-based design knowledge for SSE [5]. As a recent analysis of 14 smart service projects has shown, there is a wide variety of methods employed but in none of the investigated projects, any method specifically design for digital services or smart services was used [2]. At the same time, several established methods are applied for the engineering of Smart Service Systems in practice and appear to be suitable for this task [2]. Against this background, we pose the following research question: How can existing methods for designing digital service be combined in a real-world scenario?

We consider this research question as timely and relevant, as it is not required to "reinvent the wheel" but identify existing suitable methods and combine them with new methods specific to digital services. Our research aims to provide insights on both the suitability of different methods for the task but also their combination.

To address the research question, we apply Action Design Research (ADR) as the leading paradigm. It describes the systematic learning from the collaboration between practitioners and researchers in real-world settings to design an artifact. ADR is organized in four stages (1) problem formulation, (2) building, intervention, and evaluation, (3) reflection and learning, and (4) formalization of learning [6]. As previous research has shown, ADR is suitable for transferring knowledge for innovation in the practice $[7,8]$. We consider ADR suitable for our research, as it allows us to apply and evaluate methods in a real-world scenario. The intended outcome is organizational knowledge of how digital service innovation can be supported by a set of existing methods. This combination of methods can be considered as the artifact to be designed.

The remainder of this paper is structured as follows: After this introduction, we provide the conceptual foundation, followed by the research approach. The fourth section covers the case study and project organization. This is followed by a discussion of the results. The paper closes with a conclusion and an outlook.

\section{Conceptual Foundation}

Service Systems are a configuration of people, processes, and technology to co-create value. Digital Service Systems utilize digital technologies such as cloud computing, big data, and artificial intelligence as fundamental system elements for the provision of resources, competencies, or value creation. Therefore, value co-creation is mainly based on data [9]. Furthermore, it should be noted that there is a difference between digital and smart services [10]. Smart services are therefore considered as a subset of digital services, as they additionally include the integration of connected objects (smart products). It should be noted that digital services and smart services are often used interchangeably, as the stricter distinction has been proposed only recently.

Service Systems Engineering (SSE) [5] refers to the systematic design of Service Systems and incorporates processes, models, and techniques. Processes for SSE include the DIN SPEC 33453 [3], Recombinant Service Systems Engineering [4], and Smart Service Engineering [11]. They mainly provide a set of phases and activities, which help to structure the overall engineering endeavor. Another set of contributions for SSE consists of concrete methods that guide individual activities through models, e.g. 
Design Thinking for Industrial Services (DETHIS) [12] or the Smart Service Canvas [13]. To distinguish the four sets of methods, we introduce the categories "digital service specific methods" (DSM), existing "service engineering methods" (SEM), methods regarding "user-centered design" (UCD), and "general-purpose methods" (GPM). These categories represented existing methods and practices, which are applied for different purposes. Methods of the GPM category are the most general ones, e.g. from social research or general management. UCD methods are used within agile projects with innovative character to ensure that the resulting products are accepted by the user. While UCD can be applied to any kind of technical or digital product, service, or process, SE methods are targeted at the engineering of services. Finally, DSM consider the specifics of digital services, such as data, devices, and analytics.

Based on the insight that a single process model will not be suitable for a large variety of project settings, the concept of Situational Method Engineering (SME) [14] was proposed. It aims to flexibly combine various methods to adapt to the development process depending on the individual situation at the beginning of the project. However, it requires formal modeling of methods (fragments) and their storage in a method base to flexible combine them at the beginning of a project. A study by Clarke and O'Connor has identified eight groups, 44 factors, and 170 sub-factors that influence the selection of methods [15]. For smart services, there are typically agile approaches employed. They are less formalized, and the choice of methods is not fixed at the beginning of the project. Rather, the agile project team continuously review and adapt their way of working, e.g. during "retrospectives".

\section{$3 \quad$ Preparing the Action Design Research Project}

\subsection{Problem Formulation}

The first step of the ADR approach is problem formulation. Based on the state of the art, we can identify two problems: (1) DSM are unknown in practice, and (2) existing process frameworks for SSE may propose a set of methods but do not provide guidance for their combination. The ADR process can help to solve both aspects of the problem. DSM can be transferred to the project setting through the researcher, which also fulfills ADR principle 2: "Theory-ingrained artifact". For that, a list consisting of 30 methods was created, which serves as the basis for method selection in each iteration (Table 1).

As indicated in Table 1, the method list is largely based on the methods mentioned in the appendix of DIN SPEC 33453. Although the DIN SPEC 33453 is aimed at digital service systems engineering, there were no DSM mentioned. Therefore, we added DSMs that were cited in the 2020 edition of a textbook on data-driven service engineering and management [16] or recently published at information systems conferences. Due to the large number of methods proposed by academia, the list cannot be considered exhaustive. However, as the compiled list contains methods for various purposes in service innovation, we are confident that it is sufficient in a real-world project. 


\subsection{Introduction of Case}

We collaborated with a medium-sized German software company, which we refer to as ALPHA in this paper. It develops solutions for product cost calculation based on a common platform. The products are targeted mainly at car manufacturers and their suppliers. To be competitive in the market, the company aims to expand its product range with a new smart service, known as predictive costing, which supports cost estimation. If a car manufacturer submits a request for an offer to a supplier, they usually have little time to deliver a valid offer in terms of costs to the car manufacturer. The planned service is intended to have a supportive effect on this process. As the innovation project for the predictive costing service is an instance for this class of problems, it fulfills the ADR principle 1 "practice-inspired research". To jointly solve this service innovation problem in a structured way, i.e. use appropriate methods, is the goal of the project.

Table 1: Overview of considered methods

\begin{tabular}{|l|ll|}
\hline Type & Methods & \\
\hline GPM & 5 Why's [3] & Idea-Contest [3] \\
& 9-P Marketing Mix [3] & Interview for Empathy [3] \\
& ABC-Analysis [3] & MoSCoW- Prioritization [3] \\
& Brainstorming [3] & Nightmare Competitor [3] \\
& Conjoint-Analysis [3] & Shadowing [3] \\
& Environment Analysis [3] & Stakeholder Analysis [3] \\
& Expert Interview [17] & Stakeholder Map [3] \\
& How Might We-Questions [3] & SWOT-Analysis [3] \\
\hline UCD & Customer Journey [18] & Persona [3] \\
& Digital Mock-Up [3] & Prototyping [3] \\
& Low-Resolution Prototyping [3] & User Story Mapping [19] \\
& Pains \& Gains [3] & Value Proposition Canvas [3] \\
\hline SEM & Customer Journey Mapping [20] & Minimum Viable Service [3] \\
& Job Mapping [3] & Service Blueprinting [3] \\
\hline DSM & Information Service Blueprint [21] & Smart Service Canvas [13] \\
\hline
\end{tabular}

Long-term support is provided as the partner company is willing to develop a new smart service. One researcher assumes the role of the action researcher, while employees of the company are the practitioners. The development process is led by the action researcher in consultation with the partner company. The selection, application, and evaluation of these methods were discussed with the second researcher to ensure state-of-the-art guidance for the project as well as effective learning and reflection. In conjunction with the knowledge of the practitioners regarding the currently used technologies and their potentials, the ADR principle 4 "Mutually influential roles" is addressed. Additionally, this setup represents an inter-organizational collaboration often found in SSE [22]. Using the set of roles proposed by Anke et al., the company can be characterized by the "Project Sponsor" role, while the university took over the "Digital Innovator" role [22]. 


\subsection{Project Setup and Process Model}

As an overall project structure, the basic process of DIN SPEC 33453 was chosen, which describes an agile process with the phases analysis, design, and implementation [3]. These phases are connected by a decision point and can be conducted in any sequence [3]. While other process models for designing Digital Service Systems might be equally suitable, we chose it as we expect it to become more widely known in the future due to its governance by an established standardization body.

The overall project was conducted from April to June 2020. In line with the agile approach of DIN SPEC 33453, it was subdivided into iterations to facilitate feedback and reduce risk. Each iteration begins with the decision on a method that appears appropriate. For its selection, the iteration objective, and the situational factors (conditions) are considered. For example, the "idea generation" activity of the analysis phase is characterized by creativity and cooperative knowledge exchange [3]. Workshops are an organizational format that is suitable for these specific requirements [23] but limits the set of applicable methods, as not every method for generating ideas can be applied in a workshop. For generally applicable methods, it needs to be decided on whether they are suitable for the given context. A qualitative approach is being taken to answer this question. A method is to be considered "suitable" if it creates results that can be used in a subsequent iteration. In the next section, the planning, execution, and results of each iteration will be presented in more detail.

A total of five iterations were conducted to design the predictive costing service. Iterations I and II are part of the analysis phase of the DIN SPEC process model. After that, a decision had to be made on whether the service idea will be further pursued. Following the positive decision, iteration III focused on a more detailed elaboration of customer demands. The decision after that iteration was to pursue activities of the design phase. Iterations IV and V are therefore in the design phase, as the established understanding was used for the development of a service concept. Table 1 provides an overview of the methods and settings for each iteration.

Table 2: Overview of iterations and applied methods

\begin{tabular}{|l|l|l|}
\hline Iteration Objective & Applied Methods (Type) & Setting \\
\hline $\begin{array}{l}\text { I. Identify Innovation } \\
\text { Potentials }\end{array}$ & - Customer Journey Mapping (SEM) & Workshop (digital) \\
\hline II. Idea Assessment & - Expert interviews (GPM) & Meetings (digital) \\
\hline $\begin{array}{l}\text { III. Elaborate Customer } \\
\text { Assumptions }\end{array}$ & - Smart Service Canvas (DSM) & Workshop (digital) \\
\hline $\begin{array}{l}\text { IV. Complete the Value } \\
\text { Proposition }\end{array}$ & $\begin{array}{l}\text { - Smart Service Canvas (DSM) } \\
\text { - How Might We (GPM) }\end{array}$ & Individual work \\
\hline $\begin{array}{l}\text { V. Design the Service } \\
\text { Concept }\end{array}$ & $\begin{array}{l}\text { - Information Service Blueprint (DSM) } \\
\text { - Smart Service Canvas (DSM) }\end{array}$ & $\begin{array}{l}\text { Workshop (digital } \\
\text { \& face-to-face) }\end{array}$ \\
\hline
\end{tabular}

Subsequently, details of each iteration are provided based on the following structure. It relates to the "building, intervention, and evaluation" phase of the ADR process: 
- What was the initial situation and objective of the iteration?

- Which methods were considered and how were they selected?

- How were they applied and which results did they yield?

Unlike other ADR projects, we did not develop an IT artifact, as a selection and combination of innovation methods is an organizational artifact. Therefore, ADR principle 3 (Reciprocal Shaping) did not apply in our study. To address the ADR the principle 5 "Authentic and concurrent evaluation", we gathered feedback after each workshop. Participants were asked (1) if the applied method or parts of it was known in advance, (2) if the objective were achieved, (3) if the method yielded a meaningful result that could be used further. Additional feedback was collected on potential improvements and positive aspects of the method. This fulfills the ADR principle 6 (guided emergence), as it helps to iteratively design the desired artifact. It also helped us to understand if the introduction of these new methods was rather difficult. After each iteration, the researcher reflects upon the effects of the applied method, which addresses the ADR phase "Reflection and Learning".

\section{$4 \quad$ Application and Evaluation of Methods}

\subsection{Iteration I: Identify Innovation Potentials}

Initial Situation and Objective: The starting point of service development is a rather unclear idea of a predictive costing smart service. The targeted customer segment as well as the outgoing customer process are not sufficiently clear to the practitioners at the beginning of the development. The physical presence of all participants cannot be assumed, which is why methods and technologies must be used that allow execution over the Internet. New service ideas are based on known or assumed customer needs. Within the analysis phase, they can be identified and prioritized [3]. Subsequently, the service concept can be developed from an understanding of customer problems. Possible methods to tackle this objective are e.g. Interview for Empathy, Expert Interview, Job Mapping, Customer Journey Mapping, Shadowing, or the Smart Service Canvas. To speed up the development process, assumptions regarding the customer are made in the first iteration. Subsequently, the service concept is developed incrementally. Its realization as a prototype allows the verification of the assumptions of the customer.

Applied Method and Rationale for its Selection: A suitable method is Customer Journey Mapping (CJM). It helps to describe the service process from a customer point of view and improve the understanding of customer experience during the use of the service. Unlike service blueprinting or multilevel service design, or customer experience modeling, the customer process, ("journey"), is considered holistically in customer journey mapping. Instead of using a General Purpose Modeling Language and focusing on a service system or a single service provider, a holistic approach is used here [24]. The chosen organizational setting is a workshop, which has been identified as suitable for the collection and sharing of ideas [23], including CJM [24]. 
Application of Method and Results: A total of five persons, aged 35 - 45, from the departments Research \& Development (R\&D), product management, sales and consulting participated in the workshop. All results were documented by the moderator in "Draw.io" using a shared screen. In the beginning, the participants were instructed on the method and its application. After that, a persona was modeled to represent a typical user of the service. Based on this, the customer journey for the current service process (AS-IS) is modeled. Using a voting scheme, all workshop participants could identify customer touchpoints, which were considered particularly positive or negative on the overall experience, the so-called "moments of truth". Negative touchpoints represent potential sources for innovative ideas that improve the customer experience. In the last step of the workshop, these innovation potentials were jointly identified. After the workshop, identified innovation potentials were evaluated through a first technical analysis and a rough estimation of development cost. The workshop resulted in a definition of a persona with 24 attributes as well as a customer journey with eleven touchpoints and six moments of truth. All the six moments of truth were identified as negative influences on customer experience. Based on that, a potential innovation idea for predictive costing service was identified and documented in the form of a mind map.

Evaluation: The gathered feedback on the iteration was positive, as all participants stated the workshop achieved its objective, and only one participant said that no meaningfully usable result was created. 2 of 5 participants stated they had not known the method used beforehand. Positive feedback was received for structuring the method introduction using an example before each process step. Improvement potential was identified regarding time planning. Especially for the task "Model Customer Journey" participants wanted more time, which was interestingly the part that already took more time than originally allocated for it.

Reflection and Learning: The noted insufficient time for designing the customer journey is most likely attributable to the relatively high level of detail of the produced method artifact. To account for this, it seems reasonable to start with a more general method, e.g. the customer perspective of the Smart Service Canvas.

\subsection{Iteration II: Idea Assessment and Follow-Up Decision}

Initial Situation and Objective: The second iteration aims to examine whether identified innovation potentials are promising enough to be pursued further or whether new ideas must be searched for. To this end, insights into the related problem "carry-over part analysis", especially the frequency, are to be required. Carry-over parts are elements, which can be used in multiple products with modification. As other vendors in the market are already offering solutions for carry-over part analysis, it is important to understand its relation to the potential new predictive costing service. Generally, suitable methods are e.g. Interview for Empathy or the Expert Interview, "to be" Customer Journey, and Idea Contest.

Applied Method and Rationale for its Selection: The expert interview is a method that is suitable for data collection when the knowledge of the expert to be interviewed appears useful in the design, implementation, or control of problem-solving. The interview attempts to reconstruct (explicit) expert knowledge and to gain useful insight from 
this. Characteristics of expert interviews are the thematic focus, the use of technical terminology, and the communication of all participants at eye level [17].

Application of Method and Results: In total, three interviews were conducted. Selected experts were two product managers as well as a customer, who is the Head of Cost Engineering and Order Design of an automotive supplier. The duration of the interviews was one hour for each product manager and 30 minutes for the customer. The execution is divided into three phases: preparation, interview, and follow-up. The preparation aims to make the actual interview as efficient as possible. Specifically, the interviewer familiarized himself with the topic and elaborated a guideline with relevant questions. Within the preparatory phase, the questions are forwarded to the interviewee, so that they can prepare themselves for the interview, too. The interviews are conducted digitally through the collaboration tool Microsoft Teams. After a short introduction at the beginning of each interview, the questions sent in advance are answered by the expert and recorded in writing by the interviewer. After successfully conducting all three expert interviews, the results are processed and consolidated. Similarities and differences within the answers are identified. This serves as a basis for discussion as to how the developed innovation potential "equal part analysis" should be pursued.

Evaluation and Learnings: The results and the subsequent discussion helped to make an informed decision on the follow-up of the innovation potential. In addition to the decision-making discussion, the expert knowledge collected is useful and valuable for further service development. Due to the intensive preparation of the appointments, it was possible to hold technical and efficient discussions. Expert interviews are suitable for situations in which in-depth knowledge is required and where a common knowledge base and technical language already exist between the participants.

\subsection{Iteration III: Elaborate Customer Assumptions}

Initial Situation and Objective: According to DIN SPEC 33453, the identification of innovation potentials is followed by the structured elaboration of customer assumptions regarding the innovation potential. In this step, it is important to understand what the customer is doing, what goals he pursues, and which circumstances are inhibiting or promoting, e.g. with Shadowing or the Smart Service Canvas. Ideally, this is done in collaboration with potential customers. Due to external influences, this was not possible for this iteration. The availability of the company's employees, as well as the willingness of customers to spend time on this task, was low due to other priorities (mainly caused by the COVID-19 pandemic). To create high-quality results, this iteration is based on the employees with high customer contact, as they are available for a sufficiently long period. Meetings and workshops could still only be held online.

Applied Method and Rationale for its Selection: The first workshop shows that a less straightforward and more interactive method should be chosen. A structured yet flexible approach for the analysis, development, and description of smart services is the Smart Service Canvas (SSC) [13]. It builds on the Value Proposition Canvas (VPC) [19] and extends it with smart service specific aspects, which classifies it as DSM. The SSC is organized into the value perspective, the customer perspective, the ecosystem 
perspective, and the fit between these perspectives (see Figure 1). As one of these perspectives focuses on the customer, this section of the SSC should serve as the basis for the workshop. The customer view is based on the customer profile of the VPC and includes the fields Customer Routines and Jobs, Customer Pains, and Customer Gains. These are supplemented by the fields Context of Customer Tasks and Contextual Things and Data. A customer view is recommended for each customer segment to be considered [13]. We expect the SSC to support gaining a structured understanding of the customer and elaborate on the service using the other perspectives at a later stage.

Application of Method and Results: To prevent the timing problems that occurred in the first workshop (Iteration 1), the time-boxing technique was applied in this iteration. Time-boxing was originally applied in agile software development to restrict the available amount of time for a task. This should lead to a selection of the most important tasks, which fit in the defined time box and thus lead to an improvement in software quality [25]. In our case, two workshops were planned with three slots of 40 minutes each to address the modeling of aspects persona, Customer Gains, Customer Routines and Jobs, Customer Pains, Context of Routines and Jobs, Contextual Things and Data. The workshop was conducted using Microsoft Teams and all results were continuously documented in a shared "Draw.io" document. The four participants were aged $35-45$ and worked in the departments R\&D, product management and sales. The result of the workshop is another persona with 22 attributes. The SSC customer perspective could be filled with 13 entries for Customer Gains, 11 for Customer Jobs, 19 for Customer Pains, 12 for Context of Customer Jobs, and 10 for Contextual Things and Data.

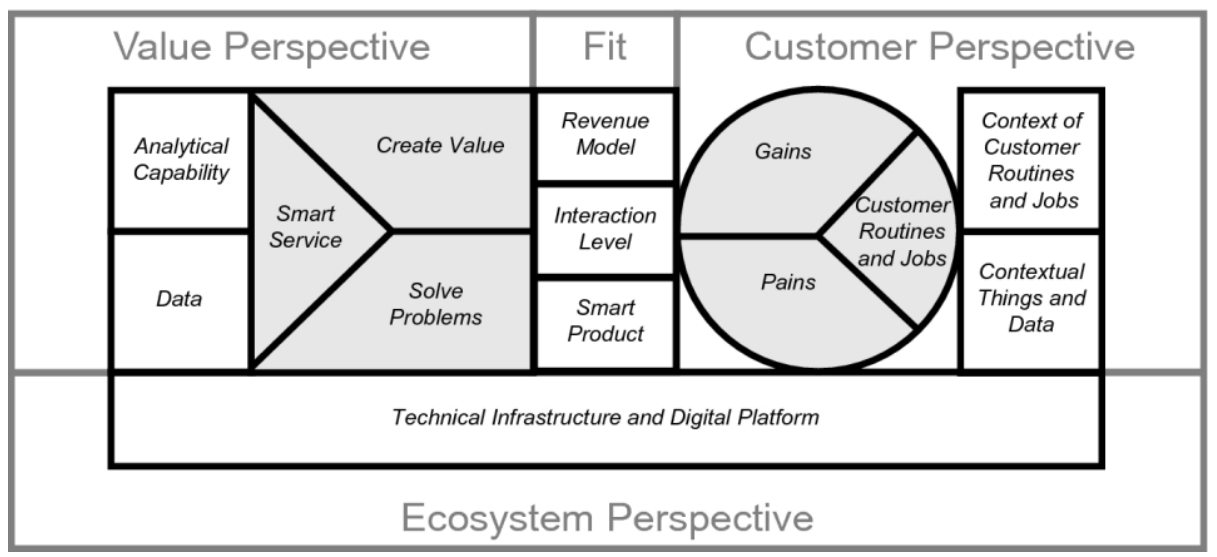

Figure 1: Smart Service Canvas [13]

Evaluation and Learnings: The creation of the persona was significantly faster than in the first workshop. According to the principle of time-boxing, the gained time was transferred to the task modeling of Customer Gains. Due to the economic situation of the company, fewer people took part in the second workshop day. This resulted in a lower communication effort, which saved time that was added to the discussion on Contextual Things and Data. The classification of Customer Gains and Jobs/Routines resulting from the literature proved to be difficult and not clear-cut. For this reason, this 
differentiation was dropped in the second workshop. It was also found that many Customer Gains are mutually dependent. The Contextual Things and Data field received special attention within the workshop, with a focus on the area of data.

The feedback of the workshop participants shows that the method performed was either not known among the participants or was not known in the smart service-specific form. The objective of the workshop has been achieved and the result has been evaluated as reusable. On the positive side, an increase in the participants' understanding was recognized. The structure of the workshop and the time organization was also positively noted. For even more efficient meetings of this kind, a stronger usage of an example scenario was asked for. The customer's perspective of the SSC can be used when an identified customer segment must be investigated. It is important to limit customer activities, which are to be considered within the SSC. Therefore, the method is not suitable for an exploratory approach. However, in the initial phase of service engineering, the open design of the SSC reveals strengths through its flexibility.

\subsection{Iteration IV: Complete the Value Proposition}

Initial Situation and Objective: The results of the first two workshops in Iteration I and Iteration III were able to provide a comprehensive understanding of the customer. Based on these findings, the first thoughts on the actual service offer are now being made. The goal of this iteration is to formulate the service's value proposition. This value proposition should be the basis for the initial design of the service concept. The service concept in turn should be sufficient as a basis for an initial prototype.

Applied Method and Rationale for its Selection: In this iteration, we focused on the value perspective and the ecosystem perspective of the SSC. For that, a basic idea of the service is required first. Due to holidays, short-time work, and pandemic-related restrictions, a workshop-format implementation was infeasible for the targeted time frame of this iteration. Therefore, we needed a flexible method that supports creativity in service development. One of them is to ask result-oriented questions, the so-called "How Might We"-questions. They aim to trigger creative solution approaches for relevant customer problems [3]. This approach is based on two assumptions: Firstly, a general common understanding has been already established so that this step can be carried out individually and does not necessarily require the organizational framework of a workshop. Secondly, the value perspective can be filled with the help of resultoriented questions. The relevant fields are Smart Service, Create Value, Solve Problems, Analytical Capabilities, and Data [13]. The ecosystem view describes the digital platform and technical infrastructure that underlies the smart service. The technical infrastructure includes, for example, the necessary hardware for power supply, but also the required network connection. The digital platform encompasses the ecosystem on which the smart service is based [13].

Application of Method and Results: The basis for the creation of the "How Might We"-questions are the customer problems of the SSC's customer perspective. At first, a thematic clustering of the problems is carried out here. Subsequently, the corresponding questions are derived from it. The preparation of the questions is iterative, to ensure that they are neither too broad nor too narrow for the required level of creative 
freedom. The questions were sent to each participant and answered individually. An individual discussion of the answers takes place after that. The result of this iteration first thoughts on the design of the new smart service. It also provided a reason to discuss the differentiation with the competition. It was also determined that the original service positioning had to be modified: Instead of a general similar part service, the focus shifts towards target price offerings, i.e. a specific form in the preparation of quotations.

Evaluation and Learnings: The method used by the "How Might We"-questions is well suited as a creative solution-oriented introduction. The value perspective of the SSC helped to thematically structure the answers. Individual elaboration seems to be possible if a common understanding of the topic has been established in advance. The integration of an initial definition question ensured that all participants had considered the content of the same topic. This increases the response quality and enables the combination of individual solution proposals. However, the high flexibility must be paid for through high effort in the preparation of the questions, as well as in the follow-up through individual discussions and the evaluation of the answers.

\subsection{Iteration V: Design the Service Concept}

Initial Situation and Objective: The goal of this iteration is to create a service concept in a structured form. The quality of the result should be sufficient for the creation of an initial simple prototype. Initial considerations from previous iterations are to be incorporated into the concept creation. Based on the results, the value perspective of the SSC is to be refined. To tackle these objectives potential methods are e.g. Job Mapping, Digital Mock-up, Paper Prototyping, and (Information) Service Blueprinting.

Applied Method and Rationale for its Selection: Service Blueprints are structured visual descriptions of a service delivery process [26]. It allows the separation of tasks performed by the customer and backstage activities. Information Service Blueprint (ISB) is a variant of Service Blueprints for Information Intensive Services (IIS) [21]. The ISB is structured in a matrix of layers and phases, to which the individual actions are assigned. The default structure of the ISB comprises the seven rows Customer Action, Information, Information Delivery System (IDS), Information Production System (IPS), and Partners. The IDS and IPS rows are divided into Information and Communication Systems (ICT Systems) and Roles of Employees. This is completed by the horizontal grouping of activities into the seven phases of objective attainment in an IIS process: Define, Prepare, Execute, Monitor, Modify, and Conclude [21]. The first row of the ISB default structure lists the customer's activities, while the second row describes the information content. The rows IDS and IPS shows which roles of the employees, respectively of the ICT systems, participate in the generation and provision of the information. The bottom row represents the partners of the provider network that may be involved in the service process [21]. It is highly recommended to customize the structure of the ISB according to individual needs and the intended scope.

Application of Method and Results: The workshop is carried out on two dates with the partial physical presence of the participants. Two employees of the R\&D department and one member of the company's product management department are involved. As a starting point, an overview of the Service Blueprint method is given, followed by 
the ISB. The workshop is organized in three phases according to the ISB design approach: Customization, Blueprinting, and Analysis. In phase one, a customized ISB is created, which is used to design the target service. Depending on the purpose, the default structure of the ISB can be adjusted by deleting, reworking, splitting, consolidating, or extending the rows. The initial step in phase one is to define the scope of service blueprinting. Here, the related customer segment and the participants of the design process are determined. Step two adjusts the rows of the ISB. The IIS is drafted in phase two. All components of the previously defined ISB are traversed row by row. The exact sequence of the rows to be traversed can be varied, provided that the customer-oriented perspective is valued. Finally, for this phase, the ISB is divided into the individual columns that categorize the service process. The third and final phase involves the analysis of the designed IIS. First, the Service Blueprint is thoroughly reviewed to ensure that no important points are missing. The final step is to look for ways to improve the design. If necessary, a further breakdown of customer actions or customer information may also be carried out beyond phase three [21]. The completed ISB for the predictive costing service is shown in Figure 2. It shows the ISB in the adapted version, as it was used in the workshop. The rows Customer Actions, Information, and ICT Systems were adopted from the default structure. For the optimal mapping of the Predictive Costing process, the rows Algorithm, Data Location, as well as Internal and External Data Provider were introduced. They emphasize the data-heavy nature of the service design developed in this workshop. After the workshop, the existing contents of the SSC value perspective were refined. The discussed findings and the developed service concept from the ISB workshop are incorporated. The result is a further elaborated value proposition of the service.

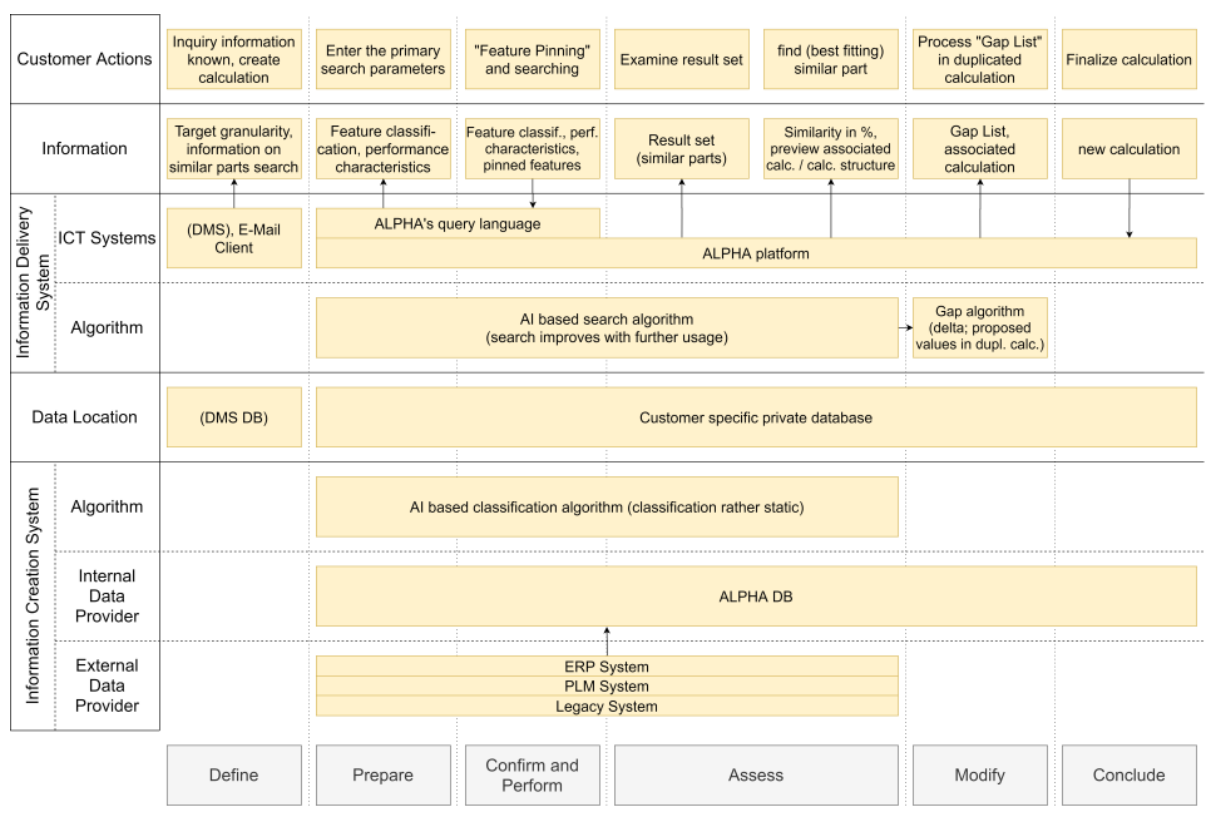

Figure 2: Workshop Artefact "Information Service Blueprint" (own depiction) 
Evaluation: A structured, comprehensive service design was successfully developed in two workshop appointments. In the beginning, the high degree of abstraction of the method, as well as the high flexibility, was perceived as challenging. However, this was successfully addressed with an iterative approach. Like the CJM method, ISB is particularly suitable for "happy path"-representations. The results of the SSC were a useful basis for the work on this task. By dividing the service process into seven phases, we discovered new customer steps that were not considered before. The ISB helps to discuss specific details of the service, as it shows how individual steps and the various systems interact with each other. Through the discussion within the workshop, also a new customer segment for the service was identified. The first result, classified as a "convincing first draft", can be transferred to a Paper Prototype in a further step. It may also be useful for a discussion with customers.

Reflection and Learning: After several iterations, the SSC proves to be a viable tool to keep an overview and consecutively enhance the service while also keeping in check, that the value proposition aligns with the customer needs in the end.

\section{$5 \quad$ Discussion and Formalization of Learning}

The overall project can be considered as a success, as a useful service concept was collaboratively developed within the Action Design Research approach. Several artifacts were created, which represent a growing understanding and advancement in the development of a new service. Our research yielded the following findings:

1. All identified tasks could be supported with a method from our pre-compiled list, which contained DSM, SEM, UCD, and GPM types of methods.

2. All selected methods were found to be suitable as they created useful results that could be further elaborated and reused in subsequent iterations.

3. The combination of methods is not only possible but also particularly useful. It turned out that they helped to provide structure and guidance for the service innovation project, e.g. through different perspectives and levels of detail.

However, the variety of methods poses a high demand on the competence of project participants. DSM were not known to most practitioners, which underlines the findings by Wolf et al [1] and Anke et al [2]. Even more established methods like Customer Journey Mapping required an introduction to the participants. Being aware of a certain method and its purpose, however, is not enough. We found that many details needed to be taken care of to apply the selected methods effectively.

Besides the practically relevant result, the learning regarding the research question must be considered. In phase four of the ADR method, the learning should be formalized. For that, the ADR principle 7 "generalized outcomes" needs to be applied. The main result of our study is a selection of methods and their combination to support the systematic design of a new digital service. For that, we (1) extracted the chosen methods used in the project, (2) identified and labeled the output of each applied method, and (3) connected the methods based on their input-output-relation. A visual representation of the method combination is shown in Figure 3. 
Starting from an initial service idea, the methods on the right-hand side are focused on advancing the understanding of the customer and its problems. These are the input for the customer perspective of the Smart Service Canvas. The link to the value proposition is achieved using the "How might we?"-method. A detailed service concept for the developed value proposition can then be elaborated using the Information Service Blueprint, as shown on the left-hand side of the figure. It has also helped to improve the value proposition, as indicated by the dotted arrow. The figure indicates the central role of the Smart Service Canvas for the innovation process, as it combines the customer view with the value proposition view.

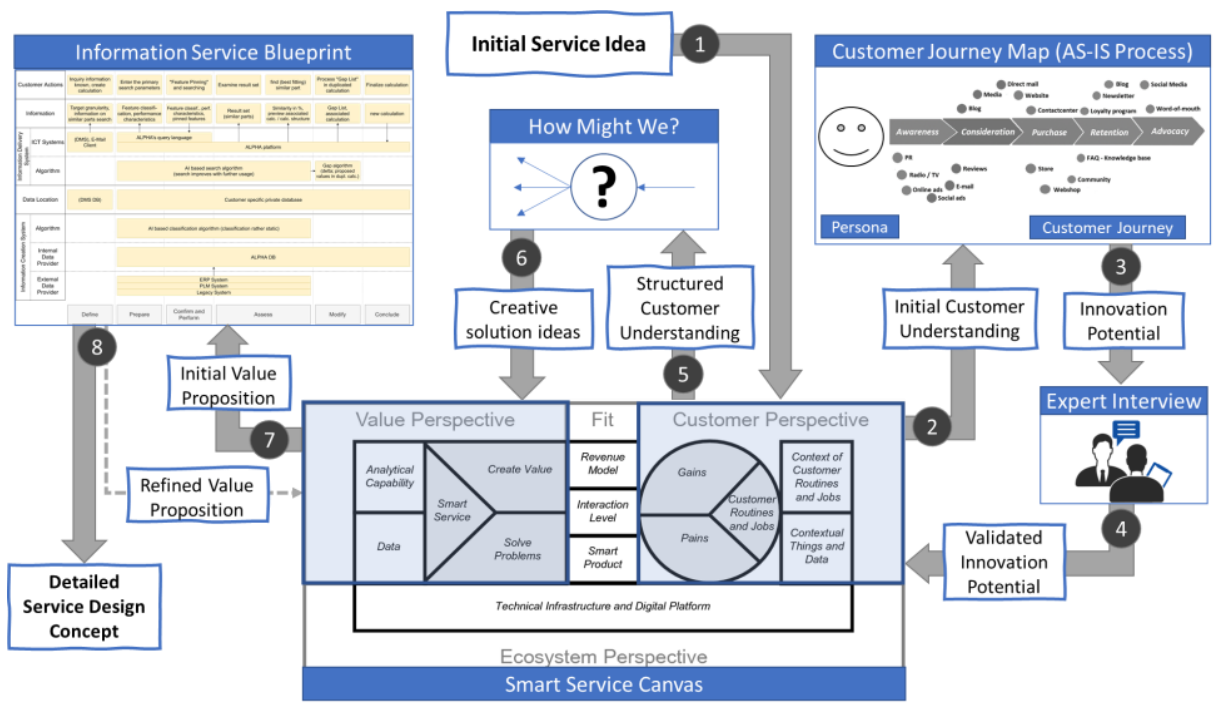

Figure 3: The proposed combination of methods for iterative service innovation

Concerning the underlying DIN SPEC 33453 reference process model, we found that the first three steps are related to "Analysis" phase activities, while steps 4 and 5 are part of "Design" activities. None of the methods contribute to the "Implementation" phase, as it was not within the scope of the ADR project in this study. However, we would like to highlight that the proposed combination of methods is not limited to projects using the DIN SPEC 33453 process model.

The result shows a combination of existing methods for digital service innovation, which was successfully applied in a real-world project. We assume, that this specific case is a representation of a digital service according to Heuermann, Duin, et al. [27]. It should be noted that the proposed combination is neither claimed to be the best nor the only one. However, we assume that it is applicable to similar innovation projects, as the selected methods are designed for these tasks. Furthermore, the input-outputrelationships between the proposed combination of methods are not specific to the concrete case in our study. Practitioners might use it as a starting point, especially if the methodological competence in an organization is low. It might also help to stimulate discussion about method combinations for both practitioners and researchers alike. 
The results of our study are subject to limitations. ADR, as a research paradigm, is inherently subjective, i.e. a different researcher might have selected different methods and/or applied them slightly differently. Also, the competence and knowledge of methods and their application highly depends on the individual. This is amplified by the application to only a single case. Finally, the underlying list of 30 methods in total was not exhaustive. Other researchers might have known different methods. Due to the many factors that influence the suitability of methods in a concrete situation, our results should be considered as an illustrative yet thoroughly conducted example. Finally, the project took place during the COVID-19 virus pandemic. Therefore, most settings had to be digital rather than face-to-face meetings. This imposed further restrictions on the selection of methods, as not all methods are suitable for digital settings. However, as remote work is a widely used way of collaborating, this is setting is not exceptional.

\section{Conclusion}

This study sheds light on the application of multiple SSE methods in a real-world project and thus helps to understand how these methods are used together to develop new digital services. It shows how methods are combined and how synergy effects are used. These are DSM, such as Smart Service Canvas, and SEM, such as the Customer Journey Map, but also GPM such as the Expert Interview. The special circumstances of the case study also show that medium-sized companies with scarce resources can successfully develop digital services using new methods. The exchange between science and practice was organized efficiently through the structure provided by ADR, which makes the use of this approach for future innovation projects promising [7].

The contributions of this study are as follows: First, we showed how existing methods for SSE can be applied in practice and evaluated their suitability for the task. We provided rationales for the selection of methods, described their application, and created results. Second, we critically reflected on the challenges and pitfalls that occurred during the usage of chosen methods. Third, we showed how the results of the applied method can be used for other methods in a later iteration. The link between inputs and outputs of methods is the basis for a combination of methods in a meaningful way. The work also helped to gain new insights into the methods used, e.g., Customer Journey Mapping was carried out in its entirety. Unlike the study by Senderek et al. [11], it was applied to a complex customer process. The Smart Service Canvas from Pöppelbuß and Durst [13] proved to be a helpful framework for structuring the development work across multiple iterations. The application of the Information Service Blueprinting [9] provides another example of a customized ISB, which can be used as an additional source of inspiration. Finally, our results indicate a set of methods that actors with the "Digital Innovator" role could use to facilitate the creation of new service ideas [22]. From our results in the investigated project, the following conclusions can be drawn:

- There was no lack of methods for the tasks at hand, but a lack of awareness for their existence and competence for their application. Hence, the focus should be on the transfer of existing methods to practice, rather than on the development of new ones. This appears to be inconsistent with a study that found that existing methods do not 
cover all phases and perspectives in SSE for smart services [28]. However, it is not contradictory as they evaluated the suitability of methods regarding smart service characteristics, while we focused on the innovation stage of a single case in practice.

- The combination of methods is helpful to coordinate work in digital service innovation projects, but as of now, there is little guidance on how to combine which methods. Therefore, future research should focus on the potential links between existing methods, e.g. through input/output-relationships.

- High flexibility in selection and combination of methods is needed to cater to different types of tasks, settings, and competencies. Thus, better means for descriptions of such settings are needed, e.g. through taxonomies of services, innovation patterns, and skillsets. Furthermore, there are no criteria to evaluate these combinations, e.g. regarding their suitability to a concrete setting. Some of the concepts from SME might be useful but should probably be less formal.

Overall, the results of this research provide an example for further advancing empirically grounded knowledge on SSE. Due to the high relevance for practice, this topic offers opportunities for collaboration between academics and practitioners.

\section{References}

1. Wolf, V., Franke, A., Bartelheimer, C., Beverungen, D.: Establishing Smart Service Systems is a Challenge: A Case Study on Pitfalls and Implications. In: Gronau, N., Heine, M., Poustcchi, K., Krasnova, H. (eds.) WI2020 Community Tracks, pp. 103-119. GITO Verlag (2020)

2. Anke, J., Ebel, M., Poeppelbuss, J., Alt, R.: How to tame the Tiger. Exploring the Means, Ends, and Challenges in Smart Service Systems Engineering. In: 28th European Conference on Information Systems (2020)

3. Deutsches Institut für Normung e.V.: DIN SPEC 33453:2019-09, Entwicklung digitaler Dienstleistungssysteme. Beuth, Berlin ICS 03.080.01; 35.240 .50 (2019)

4. Beverungen, D., Lüttenberg, H., Wolf, V.: Recombinant Service Systems Engineering. Bus Inf Syst Eng 60, 377-391 (2018)

5. Böhmann, T., Leimeister, J.M., Möslein, K.: Service Systems Engineering. Bus Inf Syst Eng 6, 73-79 (2014)

6. Sein, M.K., Henfridsson, O., Purao, S., Rossi, M., Lindgren, R.: Action Design Research. MIS Quarterly 35, 37 (2011)

7. Becker, F., Meyer, M., Redlich, B., Siemon, D., Lattemann, C.: Open KMU: Mit Action Design Research und Design Thinking gemeinsam innovieren. Eur J Mark (European Journal of Marketing) 57, 274-284 (2020)

8. Chen-Fu Yang, Tung-Jung Sung: Service Design for Social Innovation through Participatory Action Research. International Journal of Design 10, 21-36 (2016)

9. Lim, C., Kim, K.-H., Kim, M.-J., Heo, J.-Y., Kim, K.-J., Maglio, P.P.: From data to value: A nine-factor framework for data-based value creation in informationintensive services. INT J INFORM MANAGE 39, 121-135 (2018)

10. Beverungen, D., Müller, O., Matzner, M., Mendling, J., Vom Brocke, J.: Conceptualizing smart service systems. Elec. Markets 29, 7-18 (2019) 
11. Senderek, R., Ragab, S., Stratmann, L., Krechting, D.: Smart-ServiceEngineering. In: Stich, V., Schumann, J.H., Beverungen, D., Gudergan, G., Jussen, P. (eds.) Digitale Dienstleistungsinnovationen, pp. 3-15. Springer, Berlin, Heidelberg (2019)

12. Redlich, B., Becker, F., Fischer, S., Fromm, J., Gernreich, C., Lattemann, C., Pöppelbuß, J., Siemon, D., Wilms, K.: Das DETHIS-Verfahren. In: Stich, V., Schumann, J.H., Beverungen, D., Gudergan, G., Jussen, P. (eds.) Digitale Dienstleistungsinnovationen, pp. 73-88. Springer, Berlin, Heidelberg (2019)

13. Poeppelbuss, J., Durst, C.: Smart Service Canvas - A tool for analyzing and designing smart product-service systems. Procedia CIRP 83, 324-329 (2019)

14. Henderson-Sellers, B., Ralyté, J., Ågerfalk, P.J., Rossi, M.: Situational Method Engineering. Springer Berlin Heidelberg, Berlin, Heidelberg (2014)

15. Clarke, P., O'Connor, R.V.: The situational factors that affect the software development process: Towards a comprehensive reference framework. Information and Software Technology 54, 433-447 (2012)

16. Leimeister, J.M.: Dienstleistungsengineering und -management. Data-driven Service Innovation. Springer, Berlin, Heidelberg (2020)

17. Pfadenhauer, M.: Das Experteninterview. In: Buber, R., Holzmüller, H.H. (eds.) Qualitative Marktforschung, pp. 449-461. Gabler, Wiesbaden (2009)

18. Lemon, K.N., Verhoef, P.C.: Understanding Customer Experience Throughout the Customer Journey. Journal of Marketing 80, 69-96 (2016)

19. Patton, J.: User story mapping. O'Reilly Media, Sebastopol, CA (2014)

20. 2019 IEEE 21st Conference on Business Informatics (CBI). IEEE (2019)

21. Lim, C.-H., Kim, K.-J.: Information Service Blueprint: A Service Blueprinting Framework for Information-Intensive Services. Serv. Science 6, 296-312 (2014)

22. Anke, J., Poeppelbuss, J., Alt, R.: It Takes More than Two to Tango: Identifying Roles and Patterns in Multi-Actor Smart Service Innovation. Schmalenbach Bus Rev 72, 599-634 (2020)

23. Westhoff, G., Drougas, A.: Content design and methodology of seminars, workshops and congresses (2002)

24. Heuchert, M.: Conceptual Modeling Meets Customer Journey Mapping: Structuring a Tool for Service Innovation. In: 2019 IEEE 21 st Conference on Business Informatics (CBI), pp. 531-540. IEEE (2019)

25. Jalote, P., Palit, A., Kurien, P., Peethamber, V.T.: Timeboxing: a process model for iterative software development. J Syst Softw 70, 117-127 (2004)

26. Lynn Shostack, G.: How to Design a Service. Eur J Mark 16, 49-63 (1982)

27. Heuermann, A., Duin, H., Gorldt, C., Thoben, K.-D., Nobel, T.: Reifegradorientierte Konzeption und iterative Implementierung digitaler Dienstleistungen für maritime Logistikprozesse. In: Stich, V., Schumann, J.H., Beverungen, D., Gudergan, G., Jussen, P. (eds.) Digitale Dienstleistungsinnovationen, pp. 17-47. Springer, Berlin, Heidelberg (2019)

28. Marx, E., Pauli, T., Fielt, E., Matzner, M.: From Services to Smart Services: Can Service Engineering Methods get Smarter as well? In: 15th International Conference on Wirtschaftsinformatik (2020) 